Goomas, D.T. \& Ludwig, T.D. (2009). Standardized Goals and Immediate Feedback Aggregated Beyond the Work-Unit: Optimizing the use of Engineered Labor Standards and Electronic Performance

Monitoring. Journal of Applied Social Psychology, 39 (10), pp. 2425-2437. (ISSN: 0021-9029) Version of record is available from Wiley-Blackwell DOI: 10.1111/j.1559-1816.2009.00532.x

\title{
Standardized Goals and Performance Feedback Aggregated Beyond the Work Unit: Optimizing the Use of Engineered Labor Standards and Electronic Performance Monitoring
}

\author{
David T. Goomas and Timothy D. Ludwig
}

\begin{abstract}
Electronic performance monitoring can monitor employee performance, while providing proximal goals and immediate feedback. A warehouse management system was enhanced to depict goal and performance on handheld wireless computers to improve order selection in an auto-parts aftermarket distribution center. Upon the onset of the intervention of an engineered labor standard and electronic performance monitoring, performance immediately increased by 24 units picked per hour per person and was maintained for the duration of the study, an increase of $12.9 \%$. Evidence from this study suggests that performance goals and feedback can be aggregated beyond the work-unit level without decreasing the effectiveness of the intervention.
\end{abstract}

\begin{abstract}
ARTICLE
Managers in large industrial settings (e.g., distribution centers, manufacturing plants) monitor employee performance to obtain feedback to engage in goal setting, reward achievement, and, when needed, disciplinary action. Electronic performance monitoring (EPM) in a distribution center has been linked with performance goals in order to achieve bonuses (e.g., Goomas \& Ludwig, 2007). EPM means having supervisors electronically monitor the amount of work an employee is processing per day, and thereby his or her performance. Our work has been influenced, in part, by a series of studies by Aiello and colleagues (e.g., Aiello, 1993; Aiello \& Kolb, 1995; Aiello \& Svec, 1993; Douthitt \& Aiello, 2001; Kolb \& Aiello, 1996, 1997) suggesting that (a) EPM may influence productivity; and (b) if employees are involved early on in the introduction of an EPM system and they feel that their input has been incorporated in the
\end{abstract}


system that is adopted, they feel greater ownership of their work process and experience greater motivation and less stress (see also Beehr, Jex, \& Ghosh, 2001).

Earlier measures of productivity in distribution centers and warehouses were often simple algorithms and quotas. The popularity of these measures was primarily a function of their simplicity, given the limitations of existing measurement capabilities. The disadvantage, however, was that they were not very comprehensive. For example, measuring cases per hour ignored the weight, size, shape of the case, and travel distance; lines per hour disregarded the number of cases of a product line, as well as travel distance; and dollar volume per day did not take into account the size of the order. The measure most frequently used in warehouses was cases per hour, and, given the amount of variations in cases and travel distance, supervisors had to make an informed guess at the goals they wanted to assign their workers. In the absence of better productivity measurements, these informed guesses became the de facto goal in many warehouses.

\section{Productivity and Engineered Standards}

One of the most effective ways to measure productivity is the standard-versus-actual comparison (Keeney, 1994). In work measurement terminology, standard time represents the allotted time to complete the work unit, whereas actual time represents the elapsed time it takes to complete the work unit.

According to Kanawaty (1992), work study involves examination of the way an activity is being carried out, modification(s) of the operation to reduce wasteful activity, and specification of a time standard for performing the activity. One particular approach is the engineered labor standard (ELS). A task is subdivided into its elements, and each element (e.g., travel time) is given a discrete value (e.g., allocated number of minutes or seconds to travel from Point $A$ to Point B). Values are arrived at based on activity sampling, group sampling, and time-series studies, as employees in these large industrial settings perform their job duties. The time needed for a qualified worker to carry out a task is then established (Kanawaty, 1992). Work study and work measurement became easier, and more accurate performance recording was achieved when time-study software was installed on palmtop personal computers (PCs). Thus, substantially more accurate engineered standards were developed.

The merits of an ELS are many. Timings are based on direct observation and on recording by the most accurate, practicable means. Taking multiple timings-such as at the beginning, middle, and end of a shift-ensures that the standard times are representative and that allowances for fatigue are taken into account. Recorded times give a factual basis to any management-labor negotiations regarding performance standards, as opposed to the traditional practice of bargaining based on a de facto goal. Finally, in the context of the current study, ELS provide goals that can be customized for the particular work the employee is responsible for performing. 


\section{Proximity of Work Goals and Performance Feedback}

The effectiveness of goal setting to improve performance has been well established (Locke \& Latham, 1990, 2002; Sulzer-Azaroff \& Mayer, 1991). For goals to work effectively, they must describe the rate or quality of the behavior requested, describe when those behaviors are to be done, and describe the consequences contingent on attaining the goal (Sulzer-Azaroff \& Mayer, 1991).

In addition, feedback that describes an individual's performance toward attainment of the goal has been found to enhance the impact of goal setting (Locke \& Latham, 1990, 2002; Ludwig \& Geller, 2001). Many studies have suggested that feedback is best when provided immediately (Alvero, Bucklin, \& Austin, 2001; Berger \& Ludwig, 2007; Sulzer-Azaroff \& Mayer, 1991). Even short delays in the delivery of feedback have been shown to adversely impact learning (Aiken, 1968; Beeson, 1973; Gaynor, 1981).

Goals and feedback in applied settings (e.g., distribution centers, manufacturing plants) are commonly posted in break rooms and lunchrooms, and are regularly announced at employee meetings (Bateman \& Ludwig, 2003; Goomas \& Ludwig, 2007). As an example, at the start of a shift, team managers may announce a team's goal for the day. Thus, these goals are distal to the work and represent the aggregate work to be completed for the entire day. A forklift team's quota may be established as 22 pallets per hour, but performance feedback may not be delivered hourly. Instead, the previous day's performance may end up being posted each morning on the break-room bulletin board.

What these daily postings of performance goals (i.e., distal goals aggregated over a day) do not do is provide a specific goal for each work unit (i.e., proximal goal of actual performance on the work unit). Likewise, feedback for individual workers may come weeks later, in performance reviews or as part of a pay-incentive system delivered with employee paychecks. Thus, feedback delivered in applied settings is often delayed or erratic, even with adequate supervision (Komaki, 1986).

Goomas and Ludwig (2007) reported on the success of using wireless technology to deliver immediate contingencies for each unit of work to members of a stocking replenishment team in a distribution center. Handheld computers were used at an auto parts warehouse for stocking bin locations. Among other task information, goal times to complete each unit of work appeared on the handheld screen for each new task. This allowed workers to see their individualized goal for the specific unit of work, based on an ELS, immediately before (i.e., proximal to) their work unit. When these electronically delivered proximal goals were introduced, along with immediate feedback and an adapted incentive program, productivity increased nearly $24 \%$ and remained constant throughout the 10-week study. At the conclusion of their study, Goomas and Ludwig argued that it was the proximal nature of the electronically delivered goals and feedback that enhanced the performance of the warehouse employees. The often distal relationship between goal setting and performance feedback was shifted to real time, or what Baum (1994) called proximate contingencies. 
Store orders, on the other hand, typically are subdivided into multiple assignments corresponding to sections in a warehouse (e.g., a section for car batteries, a section for vehicle accessories). Each assignment may consist of picking and handling many items (between 30 and 50 products) within a section. Within each work unit of an assignment, the order selector would travel to a location and pick the requested number of units. This cycle continues until the selector finishes the overall assignment.

Whereas Goomas and Ludwig (2007) delivered goals on the wireless handheld computer one work unit at a time, in the current study, a newly developed ELS was used as a goal customized for each task assignment consisting of many work units. The present study seeks to determine if an EPM can be similarly effective by aggregating work-unit performance into a higher level task performance and offering goals at the beginning of each assignment, rather than at the beginning of each work unit.

\section{Method}

\section{Participants and Setting}

Study participants were 10 selectors (2 females, 8 males) in the accessories section of the experimental warehouse and 14 selectors ( 4 females, 10 males) in the accessories section of the comparison warehouse, owned and operated by the same corporate entity. The experimental distribution center was approximately 400,400 sq. ft. (37,200 sq. m) and was located in the Midwest. The comparison distribution center was approximately 600,000 sq. ft. $(55,800$ sq. $\mathrm{m})$ and was located in the Northeast. Both facilities operated three shifts, 5.5 days per week.

Participant ages ranged from 18 to 34 years ( $M=24.5$ years), all were employed throughout the baseline and intervention, and all were paid on the same pay scale on an hourly basis. Both groups handled the same accessory products, and the picking tasks were identical.

\section{Task}

Order pickers signed on to their radio-frequency wireless handheld computers2 and followed the instructions on the display window. 3 The handheld device was outfitted with a universal product code (UPC) scanner, speakers for auditory beeps, and a keypad for data entry.

Selectors were presented with new assignments on the handheld screen showing an assignment number, the customer order, the total number of items picked, and the number of items remaining to pick. In Figure 1, the associate has started a new assignment, having picked none (Line 5), and has 27 units remaining to pick (Line 8). Additionally, on a second screen, 
individual item information was presented, including item location, quantity ordered, item description, and part number.

Figure 1. The new fields (EXPECT END, GOAL TIME, and PREV PERF\%) added to the order summary screen.

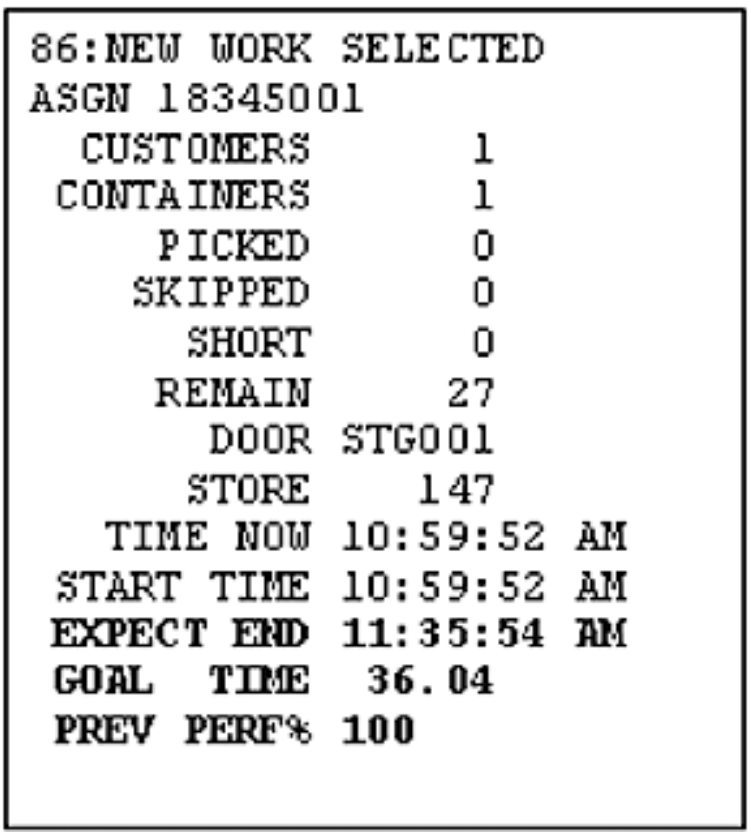

The workflow repeated by selectors for each product was the same at both warehouses. Selectors viewed the item and its location on the screen, drove a pallet jack to the location indicated, scanned the UPC of the item retrieved from the bin location, and selected the quantity of the item depicted on the screen. Selectors then entered the quantity picked into the handheld computer. This process was continued until the screen displayed "end of assignment." When the assignment was completed, selectors shrink-wrapped the pallet and transported it to the loading dock. The next work assignment would then appear on the handheld screen.

\section{Procedure}

The current study used an A-B design with a 14-day baseline and a 49-day intervention period at the experimental warehouse. Assignment goal times and performance feedback were depicted on the handheld computers. A comparison distribution center was included in the quasi-experimental design as a non-equivalent control group (i.e., not randomly assigned to groups). Selectors at this distribution center did not receive goal and performance feedback on their handheld computer screens. 
Prior to implementation of the intervention, an ELS was conducted to determine the standardized time for each assignment. The standard time was an engineered time that it should take to complete an assignment (i.e., from picking up a wooden pallet from a pallet dispenser to begin a new assignment, picking the products associated with the store order, to delivering the wrapped pallet to the loading dock). Industrial engineers calculated travel time in seconds per foot, based on the distance between each item location, taking into account distances between bin locations and warehouse layout (e.g., corners, passageways). This was added to the time it should take to handle a case, based on the product type and number of cases to be picked. Travel and case handling time were calculated for each product picked within the assignment and then summed for a total standard time, which was the engineered time allotted to complete the assignment, as indicated here:

\section{Standard time $=$ Pallet pickup time + Travel time per product + Case handling time per product + Pallet wrap time (shrink wrap)+ Travel to drop-off pallet time}

If an assignment consisted of three products, for instance, the pallet pickup time was added to the travel time to reach Product 1 , the handling time to pick n number of cases of Product 1 , followed by adding the travel time to reach Product 2 , the handling time to pick $n$ number of cases of Product 2, and then additional travel time to reach Product 3 and pick n number of cases of Product 3. Once all three products were picked, shrink-wrap time and travel time to drop off the pallet at Door $n$ were added to complete the standard time for this assignment.

A performance percentage could then be calculated for each selector after the assignment was complete. The standard time (i.e., ELS) was compared to the actual time it took to complete an assignment. For example, if the standard time was calculated to be $10 \mathrm{~min}$ and the actual work was completed in $8 \mathrm{~min}$, the performance percentage would be 125\%. Likewise, if the standard time was calculated to be $10 \mathrm{~min}$ and the actual work was completed in $12 \mathrm{~min}$, the performance percentage would be $83.3 \%$.

Prior to the intervention, all warehouse points' $x$ coordinates and y coordinates (i.e., bin locations, loading doors, aisle entry and exit points, corners, passageways) were entered into computer tables. In addition, product timings-for example, heavier products (e.g., cases of motor oil) typically require additional time to handle than do lighter products (e.g., oil filters) were added into computer tables. Distances were then calculated from the from-warehouse point (i.e., going from bin location of Product 1, having picked Product 1) to the to-warehouse point (i.e., going to bin location of Product 2 in order to pick Product 2). If Product 1 is in Aisle 10 and Product 2 is in Aisle 11, the travel distance is calculated as traveling from the Product 1 bin location to go to the end of Aisle 10, cornering, entering Aisle 11, and traveling to the Product 2 
bin location. If seconds per feet to operate a pallet jack measured by the engineer is $0.005 \mathrm{~min}$ per foot and the distance traveled is $10 \mathrm{ft} .(3.05 \mathrm{~m})$, the travel time allotted would be $0.05 \mathrm{~min}$ (3 s), and $100 \mathrm{ft}$. (30.48 m) would be allotted $0.50 \mathrm{~min}(30 \mathrm{~s})$.

\section{Intervention}

At the start of the baseline phase, the industrial engineer assembled the order selectors at the experimental warehouse for a task clarification meeting to announce the upcoming intervention. The meeting described the engineered labor standard, electronic performance monitoring, the components of the ELS calculations, demonstration of the new handheld screen, and a question-and-answer period. The order selectors were told that there would be "a couple weeks" before the engineered standards would be incorporated.

Following the 2-week baseline, the operations manager called a meeting with the order selectors at the start of the shift and announced that the adaptation of their incentive program based on the new engineered standards and performance feedback would begin, and described how it would work. The operations manager explained "With the new standards, you'll be given credit for exactly the work you are doing. Your percentage will reflect prep work, your time based on the distance you have to travel, and the number of cartons you pick."

On the day of the intervention at the experimental distribution center, the handheld computer screen was enhanced to depict the selector's goal time for the current assignment and the selector's time performance from the previous assignment (i.e., standard time divided by actual time of the previously completed assignment) on the handheld screen. Since many of these assignments took anywhere from 25 to $45 \mathrm{~min}$ to complete, a field called "EXPECT END" was programmed into the handheld screen to reflect the expected completion time (see Figure 1, Line 13). Altogether, the last three lines of the screen in Figure 1 were part of the new intervention.

Each associate at the host company was paid an hourly wage. However, if the team (i.e., the selectors, the forklift crew, and the loaders) picked an additional 5\% cases (or an additional 5\% dollar amount, depending on the team) for the month, a $\$ 200$ bonus was added to their next paycheck. The team average had to be $100 \%$ for the bonus to be delivered. The dollar amount bonus had been in place for over a year.

\section{Results}

During the 14-day baseline phase, the mean performance percentage of the 10 associates in the experimental distribution center was $88 \%(S D=6.63)$, with a range from $67 \%$ to $98 \%$. This corresponds to an average of 170 units picked per hour per person. During the intervention 
period, the mean performance percentage rose to $102 \%$ of the ELS (SD $=3.92)$, with a range from $95 \%$ to $114 \%$. The increase corresponds to an average of 194 units picked per hour per person, or 24 units picked per hour per person. The mean performance of the 14 selectors at the comparison distribution center was $82.5 \%$ for the entire 63-day study. Figure 2 shows the time-series display of the baseline and intervention results.

Figure 2. Performance percentage for order selectors in the accessory department in the Experimental Center (Exp DC) and Comparison Distribution Center (Comp DC). Daily performance percentages for the EDC appear in filled circles. Daily performance percentages for the Comp DC appear in open circles.

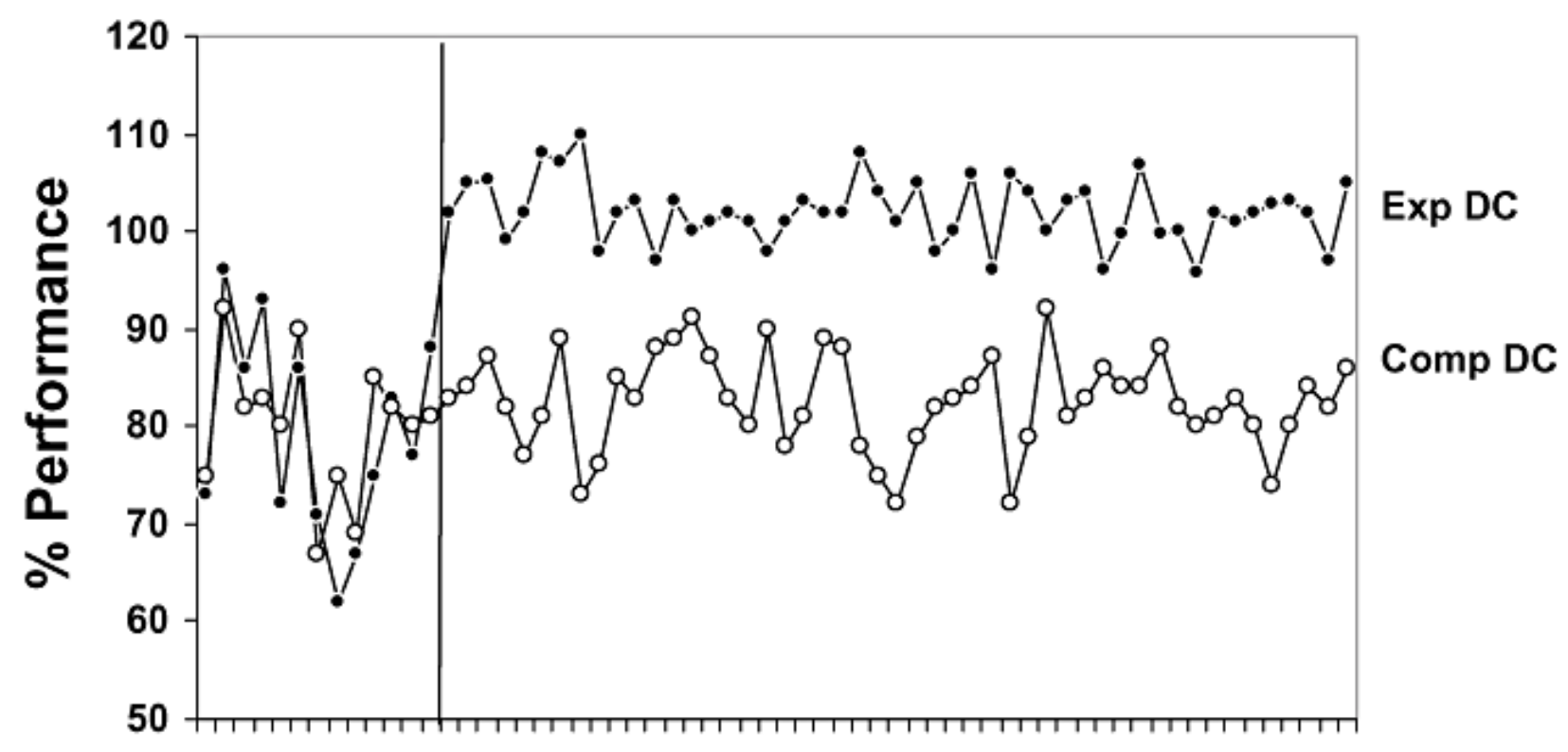

$144 \quad 7101316192225283134374043464952555861$ Baseline Intervention Consecutive Days

A t test for noncorrelated means between the experimental group and the comparison group $(N=14)$ for the baseline period shows no significant differences. After the intervention, the experimental group's performance was reliably higher than that of the comparison group, $\mathrm{t}(96)=23.10, \mathrm{p}<.001$. 


\section{Discussion}

The major findings of the present study are consistent with previous research on the robust effect of goal setting and feedback on performance in group-level interventions (Bateman \& Ludwig, 2003; Nicol \& Hantula, 2001; Pritchard, Jones, Roth, Stuebing, \& Ekeberg, 1988; Tjosvold, 1986). This study also provides additional evidence for the effective use of workplace technology to deliver goals and performance feedback more proximal to the task itself (Berger \& Ludwig, 2007; Goomas \& Ludwig, 2007; Ludwig \& Goomas, 2007). Thus, this study also supports the notion that feedback is more effective when delivered closer to the performance of the task (Alvero, Bucklin, \& Austin, 2001; Berger \& Ludwig, 2007; Sulzer-Azaroff \& Mayer, 1991).

More specifically, the intervention package in this field study replicated the intervention in Goomas and Ludwig (2007), which included the depiction of proximal goal times and immediate performance feedback on wireless hand-held computers based on newly developed engineered labor standard goals. Goomas and Ludwig reported productivity gains when feedback and performance were delivered for each unit of work.

However, in the present study, goals and feedback were delivered for an aggregate of many work units (i.e., an assignment). Selectors were given goal times for full assignment and performance feedback of the previously completed assignment on the order summary screen. This package of standardized goals, and assignment-by-assignment feedback significantly increased productivity in a distribution center.

These results seem to suggest that configuring an ELS, goal time, and performance percentage for an aggregated assignment can be just as effective in improving performance as for a single work unit (Goomas \& Ludwig, 2007). Getting the same benefit for the aggregate often means reduced hours in retooling the application software needed to configure performance for each work unit.

Previous studies have suggested that even short delays in the delivery of feedback can decrease the effectiveness of feedback to produce improvements in performance (Aiken, 1968; Beeson, 1973; Gaynor, 1981). This study showed that, across at least one level of aggregation (i.e., work unit to assignment unit), feedback can remain effective if delivered later. It is worthwhile to note that in the present study, substantial efforts were made to link validly the work unit measures to the aggregated assignment feedback through the engineered labor standards. With this, selectors were able to see their goal times for the complete assignment and adjust their pace accordingly, based on their own time checks.

As with other interventions implemented by experimenters, the experimenters sat with the order selectors in the break room at their designated break time throughout the first week of the intervention, inasmuch as such informal settings offer valuable feedback and opportunities to improve the intervention. The post-intervention feedback from the order selectors confirms Kolb and Aiello (1997) on the importance of keeping associates involved and informed of the intervention. One selector commented that "Showing the goals helps keep me focused." The 
task clarification meeting by the industrial engineer and the meeting by the operations manager were key components of the process.

In a field setting, such as this one, gains in realism may well offset concerns with internal validity (Komaki \& Goltz, 2001). However, the conclusions of this study should be treated with a note of caution, since this case study is, after all, a quasi-experimental design with a non-randomized control group and did not include a reversal. Managers of the experimental distribution center predictably were resistant to taking away the positive effects of the new technology-based goal and feedback system (see Gaetani, Hoxeng, \& Austin, 1985).

Additionally, a controlled comparison of assignment-level operations versus work-unit operations was not done in the present study. The choice to use feedback and goal configured for one work unit (Goomas \& Ludwig, 2007) or multiple work units, seen here, must be looked at more closely. This suggests that a future study directly comparing work unit to aggregate assignment level operations of goals and feedback proximity is needed. Perhaps this type of study could also aggregate productivity further to test if these operations could be effective if applied across assignments such as across a whole shift or even work week (which most companies do currently).

As more and more distribution centers go "paperless," and the work in the distribution process is presented to the workforce on wireless units (handheld, vehicle mounts, or voice units) in a variety of tasks (e.g., stocker replenishment, picking), the distal relationship between goal setting and performance feedback is shifted to real time. As a result, the impact on order selection performance can be expected to be immediate and sustained.

Applied practitioners must be cautious that the information (e.g., goal times, performance percentages) presented to warehouse associates does not interfere with the directed work. Otherwise, the workers may focus more on the timing, as opposed to performing the work. This was the reason we added the EXPECT END time on the screen. We did not want the associates wasting time trying to perform mental calculations, which could be wrong anyway, in an attempt to determine when the assignment should be completed. By referring to the order summary screen, associates could quickly view the time their assignment started (i.e., START TIME), the standard time (i.e., GOAL TIME), and the time the assignment should be completed (i.e., EXPECT END), and then get back to the business of completing the assignment. Finally, goal-setting and performance-feedback interventions may prove to be most effective when integrated with operational best practices that include engineered labor standards and electronic performance monitoring. 


\section{References}

Aiello, J. R. (1993). Electronic performance monitoring. Journal of Applied Social Psychology, 23, 499-507.

Aiello, J. R., \& Kolb, K. J. (1995). Electronic performance monitoring and social context: Impact on productivity. Journal of Applied Psychology, 80, 339-353.

Aiello, J. R., \& Svec, C. M. (1993). Computer monitoring of work performance: Social facilitation and electronic presence. Journal of Applied Social Psychology, 23, 537-548.

Aiken, E. G. (1968). Delayed feedback effect on learning and retention of Morse code symbols. Psychological Reports, 23, 723-730.

Alvero, A. M., Bucklin, B. R., \& Austin, J. (2001). An objective review of the effectiveness and essential characteristics of performance feedback in organizational settings (1985-1998). Journal of Organizational Behavior Management, 21, 3-29.

Bateman, M. J., \& Ludwig, T. D. (2003). Managing distribution quality through an adapted incentive program with tiered goals and feedback. Journal of Organizational Behavior Management, 23, 33-55.

Baum, W. M. (1994). Understanding behaviorism: Science, behavior, and culture. New York: HarperCollins College Publishers.

Beehr, T. A., Jex, S. M., \& Ghosh, P. (2001). The management of occupational stress. In C. M.Johnson, W. K.Redmon, \& T. C.Mawhinnery (Eds.), Handbook of organizational performance: Behavior analysis and management (pp. 139-166). New York: Haworth.

Beeson, R. O. (1973). Immediate knowledge of results and test performance. Journal of Educational Research, 66, 224-226.

Berger, S. M., \& Ludwig, T. D. (2007). Voice-assisted technology providing immediate feedback to reduce employee errors. Journal of Organizational Behavior Management, 27, 1-31.

Douthitt, E. A., \& Aiello, J. R. (2001). The role of participation and control in effects of computer monitoring on fairness perceptions, task satisfaction, and performance. Journal of Applied Psychology, 86, 867-874.

Gaetani, J. J., Hoxeng, D. D., \& Austin, J. T. (1985). Engineering compensation systems: Effects of commissioned versus wage payment. Journal of Organizational Behavior Management, 7, 51-63.

Gaynor, P. (1981). The effect of feedback delay on retention of computer-based mathematical material. Journal of Computer-Based Instruction, 8, 28-34. 
Goomas, D. T., \& Ludwig, T. D. (2007). Enhancing incentive programs with proximal goals and immediate feedback: Engineered labor standards and technology enhancements in stocker replenishment. Journal of Organizational Behavior Management, 27, 33-68.

Kanawaty, G., (1992). Introduction to work study (4th ed.). Geneva, Switzerland: International Labor Office.

Keeney, A., Jr. (1994). Personnel planning. In J. A.Tompkins \& D. Harmelink (Eds.), The distribution management handbook (pp. 21.1-21.21). New York: McGraw-Hill.

Kolb, K. J., \& Aiello, J. R. (1996). The effect of electronic performance monitoring on stress: Locus of control as a moderator variable. Computers in Human Behavior, 12, 407-423.

Kolb, K. J., \& Aiello, J. R. (1997). Computer-based performance monitoring and productivity in a multiple task environment. Journal of Business and Psychology, 12, 189-204.

Komaki, J. L. (1986). Toward effective supervision: An operant analysis and comparison of managers at work. Journal of Applied Psychology, 71, 270-279.

Komaki, J. L., \& Goltz, S. M. (2001). Within-group research designs: Going beyond program evaluation questions. In C. M.Johnson, W. K.Redmon, \& T. C.Mawhinnery (Eds.), Handbook of organizational performance: Behavior analysis and management (pp. 51-80). New York: Haworth.

Locke, E. A., \& Latham, G. P. (1990). A theory of goal setting and task performance. Englewood Cliffs, NJ: Prentice Hall.

Locke, E. A., \& Latham, G. P. (2002). Building a practically useful theory of goal setting and task motivation. American Psychologist, 57, 705-717.

Ludwig, T. D., \& Geller, E. S. (2001). Intervening to improve the safety of occupational driving: A behavior change model and review of empirical evidence. Binghamton, NY: Haworth.

Ludwig, T. D., \& Goomas, D. T. (2007). Performance, accuracy, data delivery, and feedback methods in order selection: A comparison of voice, handheld, and paper technologies. Journal of Organizational Behavior Management, 27, 69-107.

Nicol, N., \& Hantula, D. A. (2001). Decreasing delivery drivers' departure times. Journal of Organizational Behavior Management, 21, 105-116.

Pritchard, R. D., Jones, S. D., Roth, P. L., Stuebing, K. K., \& Ekeberg, S. E. (1988). Effects of group feedback, goal setting, and incentives on organizational productivity. Journal of Applied Psychology, 73, 337-358.

Sulzer-Azaroff, B., \& Mayer, G. R. (1991). Behavior analysis for lasting change. Fort Worth, TX: Harcourt Brace College Publishers.

Tjosvold, D. (1986). Organizational test of goal linkage theory. Journal of Occupational Behavior, 7, 77-88. 


\section{Footnotes}

2

Intermec Model CK30, which was 8.2 in. $(20 \mathrm{~cm})$ long $\times 2.8 \mathrm{in} .(7 \mathrm{~cm})$ wide $\times 1.6 \mathrm{in} .(4 \mathrm{~cm})$ high. See http://www.intermec.com

3

The dimensions of the display window were 2.25 in. $(5.7 \mathrm{~cm}) \times 2.25$ 